\title{
Optimization of Electroless Ni-P-W Coatings for Minimum Friction and Wear Using Grey-Taguchi Method
}

\author{
Supriyo Roy and Prasanta Sahoo \\ Department of Mechanical Engineering, Jadavpur University, Kolkata 700032, India \\ Correspondence should be addressed to Prasanta Sahoo; psjume@gmail.com
}

Received 22 May 2013; Revised 27 November 2013; Accepted 28 November 2013

Academic Editor: Juan J. De Damborenea

Copyright (c) 2013 S. Roy and P. Sahoo. This is an open access article distributed under the Creative Commons Attribution License, which permits unrestricted use, distribution, and reproduction in any medium, provided the original work is properly cited.

\begin{abstract}
The present experimental investigation deals with the deposition of electroless Ni-P-W coating on mild steel substrate and optimization of tribological parameters for better tribological behaviour like minimization of wear depth and coefficient of friction. Three tribological test parameters, namely, load, speed, and time, are optimized for minimum friction and wear of the coating. Friction and wear tests are carried out in a multitribotester using block on roller configuration under dry conditions. Taguchi based grey relational analysis is employed for optimization of this multiple response problem using $\mathrm{L}_{27}$ orthogonal array. Analysis of variance shows that load, speed, time, and interaction between load and speed have significant influence on controlling the friction and wear behavior of Ni-P-W coating. It is observed that wear mechanism is mild adhesive in nature. The structural morphology, composition, and phase structure of the coating are studied with the help of scanning electron microscopy (SEM), energy dispersive $\mathrm{X}$-ray analysis (EDX), and X-ray diffraction analysis (XRD), respectively.
\end{abstract}

\section{Introduction}

Most of the engineering components undergo rubbing action due to which wear takes place on the surface of the components and become useless after a certain period. Life and performance of these engineering components can be extended by applying hard coatings over the surface of the components. The thickness of coatings ranged between 10 and $500 \mu \mathrm{m}$ and their rates of deposition can provide the required product quality at relatively low capital and operating costs. Among the various metallic coating procedures based on aqueous solutions, most metals are electroplated since electroplating is technically straightforward and less expensive than electroless (autocatalytic) deposition. On the other hand, electroless deposition is of industrial importance mainly for copper, nickel, and some nickel based alloys. Industrial use of electroless deposition method continues to increase due to its good anticorrosion, antifriction, and wear protection properties. Electroless method has several advantages over electroplating technique, except for the life of the bath. The advantages include the quality of the deposit, namely, the physical and mechanical properties.
In this process, a sharp edge receives the same thickness of deposit as a blind hole does and it offers extremely bright deposits, which are comparable with electroplated ones. The desirable properties can be varied by choosing different $\mathrm{pH}$, temperature, and composition of the bath. Electroless nickel coatings have received the greatest commercial importance among the electroless coatings. Since the discovery of electroless/chemical coating process in 1946 by Brenner and Riddell [1], series of research studies have been performed and the process is accepted by various industries like electrical, aerospace, automotive, chemical, electronics, and so forth $[2,3]$. In electroless coating process, the substrate is submerged into a chemical solution called bath which consists of solution of metal ions, reducing agent, complexing agents, stabilizers, buffer solution, and so forth at a certain temperature. Because these protective coatings are chemically applied, they create deposits of highly consistent depth across all surfaces, including edges and complex interior geometries. Electroless nickel coatings are the popular variant of electroless coatings which possess some distinct collection of properties like good corrosion resistance, high wear resistance, low friction, fast plating rate, good chemical resistance, 
and so forth. Hypophosphite reduced nickel-phosphorous and borohydride reduced nickel-boron coatings have already gained immense popularity particularly due to excellent hardness, anticorrosion, and tribological properties [4-6]. The basic binary Ni-P deposit with high phosphorus content is a phosphorus supersaturated solid solution, exhibiting amorphous structure. After suitable heat treatment, the Ni$\mathrm{P}$ coating can be strengthened with the crystallization of nickel and nickel phosphide [7]. However, the hardness of the coating is degraded with excessive heating at elevated temperature. Heating of chemical deposits is done primarily to eliminate hydrogen embrittlement in the substrate and to have enhanced deposit hardness, abrasion resistance, and enhanced adhesion to the substrate. Heating can enable the absorbed hydrogen to diffuse out of the components, which gets introduced into the components during deposition processes and increases the wear resistance [8]. Remarkable improvement in wear resistance of the coatings has been reported when hard particles are incorporated [9]. Choice of the particles depends on the desired property. In the field of tribology, nickel based composite coatings can be divided into two major categories, that is, lubricating composite coatings and wear-resistant composite coatings. The wearresistant composite coatings usually have codeposited hard particles such as $\mathrm{W}, \mathrm{SiC}, \mathrm{Al}_{2} \mathrm{O}_{3}, \mathrm{~B}_{4} \mathrm{C}$, and diamond, and they usually have increased hardness and wear resistance as compared to binary Ni-P coating.

Pearlstein and Weightman [10] first presented the Ni-PW ternary alloy in 1963 and, since then, many investigations on Ni-P-W ternary alloy have been reported. Most of these studies aim to have better tribological properties or hardness of the coating or the characteristics of the deposition on the basis of the composition of chemicals of the coating and the heat treatment temperature. But the wear rate, mechanism of wear, or coefficient of friction of Ni-P-W coating may vary due to different combination of the tribological parameters like load, speed, time, type of lubricants, and so forth. Generally, the mechanism of wear of Ni-P deposit depends on the attractive force that operates between the atoms of nickel from the coating and element from the counter disk. Adhesive wear takes place when two nominally flat solid surfaces are in sliding contact. At the interface asperities, contact and bonding take place due to adhesion. These contacts get sheared during sliding, resulting in detachment of a fragment from one surface and its attachment to the other surface or formation of wear particles. According to Archard's theory of wear, shearing of the asperity junctions can occur in one of the two bodies depending on the relative magnitude of interfacial adhesion strength and the breaking (shearing) strength of the surrounding local regions. Adhesive wear is characterized by the transfer of material from one surface to the other as a form of wear debris. There are several factors which influence the adhesive wear; these are load, speed, time, hardness, degree of adhesion between the interacting surfaces, and the rate of formation of surface oxide film. If the materials are hard or have low mutual solubility then mild adhesive wear takes place. Mild adhesive wear can lead to considerable formation of oxide layer at the contacting surface resulting in a low or negative wear depth profile.
Wear and friction measurements carried out on Ni-P and $\mathrm{Ni}-\mathrm{P}-\mathrm{W}$ coatings $[11,12]$ reveal that wear resistance of the coating increases with the increase of tungsten content under a $40 \mathrm{~N}$ loading condition. This is due to the solid solution strengthening of nickel matrix by tungsten. The coefficient of friction is found to be high and further increased with the increase of applied normal load. The frictional coefficient is found to be higher in as-plated condition compared to heat-treated condition. The wear rate is correlated with the hardness value. The hardness of these coatings is also seen to increase with increasing tungsten content [13-17]. It was observed that wear rate increases with increasing load and $\mathrm{Ni}-\mathrm{P}-\mathrm{W}$ coatings show higher wear resistance. Specific wear rate is seen to be the lowest in the case of coatings subjected to heating at $500^{\circ} \mathrm{C}$. This is due to the maximum hardness of the coatings achieved by heating at this temperature. When heated beyond this temperature the specific wear rate is found to increase due to softening of coatings by grain coarsening. The increase in hardness takes place due to the precipitation of fine $\mathrm{Ni}$ crystallites and $\mathrm{Ni}_{3} \mathrm{P}$ during phase transition $[8,18-$ 22]. The hardening effect of the fine $\mathrm{Ni}_{3} \mathrm{P}$ particles is assumed to result from their higher strength and shear modulus.

As the Ni-P-W ternary alloy coating has emerged as a hard coating in the field of tribology, the tribological parameters like load, speed, time, lubricant, and so forth need to be optimized for better tribological (both friction and wear) behavior of this coating. In this experimental investigation an attempt has been made to find out the optimum combination of the tribological parameters for minimum friction and wear characteristics simultaneously. As coefficient of friction and wear both are to be minimized, so it belongs to multiresponse problem. Optimization of multiple quality characteristics is much more complicated than optimization of a single quality characteristic. Improving one particular quality characteristic may lead to serious degradation of other critical quality characteristics. To convert this multi-response problem into an equivalent single response problem the grey relational analysis is adopted. Hence, the present investigation is formulated into an optimization problem based on grey relational analysis coupled with Taguchi method. The basic aim of the investigation is to find the optimum combination of tribological test parameters for minimum friction and wear so that Ni-W-P coatings can be used in appropriate tribological applications. Moreover, the coating is characterized with the help of SEM, EDX, and XRD in order to understand the microstructural characteristics of coatings.

\section{Experimental Details}

2.1. Preparation of Substrate. Square shaped mild steel specimen of size $20 \mathrm{~mm} \times 20 \mathrm{~mm} \times 8 \mathrm{~mm}$ is used as substrate for the deposition of Ni-P-W coating. This particular dimension of the substrate is chosen in accordance with its counterpart in the multitribotester apparatus where the sample has to be fitted for tribological testing. Shaping, parting, and milling operation is performed sequentially to prepare the specimens from the raw material. Finally surface grinding process is employed to make the surface of the blocks smooth enough because the tribological characteristics of a surface may 
depend on its surface roughness. Now, as electroless nickel coatings generally follow the surface profile of the substrate, the prepared substrates in the present study should have similar surface roughness. Hence, all the substrates before coating are subjected to roughness evaluations (center line average values, $R_{a}$ ) and the substrates which showed as little as about $0.1 \%$ variation in roughness are selected for electroless Ni-P-W coatings. The roughness measurements are carried out using a surface profilometer (Taylor Hobson, Surtronic 3+) and the average roughness of $0.49 \mu \mathrm{m}$ is obtained. The samples are cleaned from foreign matter and corrosion products by wiping. After that, surfaces of the mild steel specimens are cleaned using distilled water. The specimens, after thorough cleaning, are etched with 50\% hydrochloric acid for $1 \mathrm{~min}$. Subsequently, they are rinsed in distilled water followed by methanol cleaning prior to coating.

2.2. Coating Deposition. The bath composition and operating conditions for Ni-P-W coating are selected after several trials and proper ranges of the parameters are chosen accordingly. Table 1 indicates the bath composition and the operating conditions for successful coating of Ni-P-W on mild steel substrate. Nickel sulphate is used as the source of nickel while sodium hypophosphite is the reducing agent. Sodium tungstate solution is used as the source of tungsten ion. The bath is prepared by adding the constituents in appropriate sequence. The $\mathrm{pH}$ of the solution is maintained at around 78 by continuous monitoring with a $\mathrm{pH}$ meter. The cleaned samples are activated in palladium chloride solution at a temperature of $55^{\circ} \mathrm{C}$. This is necessary because catalytic nuclei of metal $\mathrm{M}$ on a noncatalytic surface $\mathrm{S}$ may be generated in an electrochemical oxidation-reduction reaction,

$$
\mathrm{M}^{\mathrm{z+}}+\mathrm{Red} \longrightarrow \mathrm{M}+\mathrm{OX}
$$

where $\mathrm{M}^{\mathrm{Z}}$ is the metallic ion and $\mathrm{M}$ is the metal catalyst. The preferred catalyst is $\mathrm{Pd}$, and thus the preferred nucleating agent $\mathrm{M}^{\mathrm{Z}}$ is $\mathrm{Pd}^{2+}$ (from $\mathrm{PdCl}_{2}$ ). Activated samples are then submerged into the chemical bath which is maintained at a temperature between 90 and $92^{\circ} \mathrm{C}$ with the help of a hot plate cum stirrer, attached with a temperature sensor which is also submerged in the solution. The deposition is carried out for a period of 3 hours. The range of coating thickness is found to be around $35 \mu \mathrm{m}$. After the deposition, the samples are taken out of the electroless nickel bath and washed in distilled water. Then the samples are heat-treated in a box furnace. Each specimen is coated and heat-treated in air (annealed at $400^{\circ} \mathrm{C}$ for $1 \mathrm{~h}$ ) separately. The proposed scheme for the reaction mechanism in the deposition of ternary Ni-P-W is as follows [23]:

$$
\begin{gathered}
\mathrm{Ni}^{2+}+2 \mathrm{e}^{-}=\mathrm{Ni} \\
\mathrm{WO}_{4}{ }^{2-}+6 \mathrm{e}^{-}+4 \mathrm{H}_{2} \mathrm{O}=\mathrm{W}+8 \mathrm{OH}^{-} \\
\mathrm{H}_{2} \mathrm{PO}_{2}{ }^{-}+3 \mathrm{OH}^{-}=\mathrm{HPO}_{3}{ }^{2-}+2 \mathrm{H}_{2} \mathrm{O}+2 \mathrm{e}^{-} \\
\mathrm{H}_{2} \mathrm{PO}_{2}{ }^{-}+2 \mathrm{H}^{+}+\mathrm{e}^{-}=\mathrm{P}+2 \mathrm{H}_{2} \mathrm{O}
\end{gathered}
$$

2.3. Choice of Design Factors. The design factors or input parameters are the experimental parameters which are varied within a specific range to obtain a desired result of the response variables (output parameters). Basically the aim is to obtain an optimum combination of design factors for the best possible value of response variables (output parameters). There are a large number of factors that can be considered for controlling the tribological behaviour of Ni-P$\mathrm{W}$ coatings. However, review of the literature shows that the following three parameters are the most widespread amongst the researchers to control the tribological performance of coatings: load $(A)$, speed $(B)$, and time $(C)$. These three factors are considered as main design factors along with their interactions in the present study. Table 2 shows the design factors along with their levels. Three levels are selected to observe the nonlinear effect of responses due to the variation of parameters. The middle level of each parameter is considered as initial condition. With reference to this combination of parameters, this experimental investigation aims to find out the optimum combination of parameters for better tribological behavior. The levels and ranges of the design factors are so selected considering the smaller thickness of the coatings (around $35 \mu \mathrm{m}$ ). Otherwise, through coating wear may occur. For the present study the response variables are coefficient of friction and wear depth.

2.4. Planning of Experiment. The study tries to utilize Taguchi method [24] to find the best possible combination of process parameters that can achieve the desired performance of tribological behavior of Ni-P-W coatings. The process parameters that influence the quality characteristics of tribological behavior are selected on the basis of literature review. The quality characteristics that need to be improved include minimization of wear depth as well as coefficient of friction. Both quality characteristics possess the smaller the better property. The study considers three equally spaced levels for each design factor to estimate the impact of noise factors. According to the number of design factors and their levels and also considering the effect of individual factors as well as the interactions, a $\mathrm{L}_{27}\left(3^{3}\right)$ orthogonal array is selected to proceed with the experiments. The $\mathrm{L}_{27}$ orthogonal array (OA) is shown in Table 3. Here each column represents a specific factor, each row represents an experimental run, and the cell values indicate the factor settings for the run. Three factors each containing 3 levels can combine in 27 possible ways such as $(1,1,1),(1,1,2),(1,1,3),(1,2,1),(1,2,2)$, and $(1,2,3)$. When three columns of an array form these combinations the same number of times, the columns are said to be balanced or orthogonal. Thus, all the columns of this array are orthogonal to each other. As this study includes three levels so for the three individual factors the total degree of freedom is 6 ((3$1) \times 3=6)$, and for the three two way interactions the total degree of freedom is $12((3-1) \times(3-1) \times 3=12)$. So the total degree of freedom considering the individual factors as well as their interactions is 18 . So, in the present investigation, an $\mathrm{L}_{27} \mathrm{OA}$, which has 27 rows corresponding to the number of tests (26 degrees of freedom) with 13 columns at three levels, is chosen. As per the requirements of the $\mathrm{L}_{27} \mathrm{OA}$, the 1st column is assigned to the load $(A)$, the second column is 
TABLE 1: Electroless bath composition and operating condition.

\begin{tabular}{lccc}
\hline Bath constituents & Values & Operating condition & \\
\hline Nickel sulphate $(\mathrm{g} / \mathrm{L})$ & 20 & $\mathrm{pH}$ & $7-8$ \\
Sodium hypophosphite $(\mathrm{g} / \mathrm{L})$ & 20 & Temperature & $90 \pm 2^{\circ} \mathrm{C}$ \\
Sodium citrate $(\mathrm{g} / \mathrm{L})$ & 35 & Duration of coating & $3 \mathrm{~h}$ \\
Ammonium sulphate $(\mathrm{g} / \mathrm{L})$ & 30 & & \\
Lactic acid $(\mathrm{g} / \mathrm{L})$ & 5 & Bath volume $(\mathrm{mL})$ & 200 \\
Sodium tungstate $(\mathrm{g} / \mathrm{L})$ & 15 & \\
\hline
\end{tabular}

TABLE 2: Design factors and their levels.

\begin{tabular}{|c|c|c|c|c|}
\hline \multirow{2}{*}{ Design factors } & \multirow{2}{*}{ Unit } & \multicolumn{3}{|c|}{ Levels } \\
\hline & & 1 & 2 & 3 \\
\hline Load $(A)$ & $\mathrm{N}$ & 50 & $75^{\mathrm{a}}$ & 100 \\
\hline Speed $(B)$ & R.P.M & 60 & $70^{\mathrm{a}}$ & 80 \\
\hline Time $(C)$ & $\min$ & 5 & $10^{\mathrm{a}}$ & 15 \\
\hline
\end{tabular}

${ }^{\mathrm{a}}$ Initial condition.

TABLE 3: $\mathrm{L}_{27}$ Orthogonal array with design factors and interactions.

\begin{tabular}{|c|c|c|c|c|c|c|c|c|c|c|c|c|c|}
\hline \multirow{2}{*}{ Trial no. } & \multicolumn{13}{|c|}{ Column numbers } \\
\hline & $1(A)$ & $2(B)$ & $3(A \times B)$ & $4(A \times B)$ & $5(C)$ & $6(A \times C)$ & $7(A \times C)$ & $8(B \times C)$ & $9(-)$ & $10(-)$ & $11(B \times C)$ & $12(-)$ & $13(-)$ \\
\hline 1 & 1 & 1 & 1 & 1 & 1 & 1 & 1 & 1 & 1 & 1 & 1 & 1 & 1 \\
\hline 2 & 1 & 1 & 1 & 1 & 2 & 2 & 2 & 2 & 2 & 2 & 2 & 2 & 2 \\
\hline 3 & 1 & 1 & 1 & 1 & 3 & 3 & 3 & 3 & 3 & 3 & 3 & 3 & 3 \\
\hline 4 & 1 & 2 & 2 & 2 & 1 & 1 & 1 & 2 & 2 & 2 & 3 & 3 & 3 \\
\hline 5 & 1 & 2 & 2 & 2 & 2 & 2 & 2 & 3 & 3 & 3 & 1 & 1 & 1 \\
\hline 6 & 1 & 2 & 2 & 2 & 3 & 3 & 3 & 1 & 1 & 1 & 2 & 2 & 2 \\
\hline 7 & 1 & 3 & 3 & 3 & 1 & 1 & 1 & 3 & 3 & 3 & 2 & 2 & 2 \\
\hline 8 & 1 & 3 & 3 & 3 & 2 & 2 & 2 & 1 & 1 & 1 & 3 & 3 & 3 \\
\hline 9 & 1 & 3 & 3 & 3 & 3 & 3 & 3 & 2 & 2 & 2 & 1 & 1 & 1 \\
\hline 10 & 2 & 1 & 2 & 3 & 1 & 2 & 3 & 1 & 2 & 3 & 1 & 2 & 3 \\
\hline 11 & 2 & 1 & 2 & 3 & 2 & 3 & 1 & 2 & 3 & 1 & 2 & 3 & 1 \\
\hline 12 & 2 & 1 & 2 & 3 & 3 & 1 & 2 & 3 & 1 & 2 & 3 & 1 & 2 \\
\hline 13 & 2 & 2 & 3 & 1 & 1 & 2 & 3 & 2 & 3 & 1 & 3 & 1 & 2 \\
\hline 14 & 2 & 2 & 3 & 1 & 2 & 3 & 1 & 3 & 1 & 2 & 1 & 2 & 3 \\
\hline 15 & 2 & 2 & 3 & 1 & 3 & 1 & 2 & 1 & 2 & 3 & 2 & 3 & 1 \\
\hline 16 & 2 & 3 & 1 & 2 & 1 & 2 & 3 & 3 & 1 & 2 & 2 & 3 & 1 \\
\hline 17 & 2 & 3 & 1 & 2 & 2 & 3 & 1 & 1 & 2 & 3 & 3 & 1 & 2 \\
\hline 18 & 2 & 3 & 1 & 2 & 3 & 1 & 2 & 2 & 3 & 1 & 1 & 2 & 3 \\
\hline 19 & 3 & 1 & 3 & 2 & 1 & 3 & 2 & 1 & 3 & 2 & 1 & 3 & 2 \\
\hline 20 & 3 & 1 & 3 & 2 & 2 & 1 & 3 & 2 & 1 & 3 & 2 & 1 & 3 \\
\hline 21 & 3 & 1 & 3 & 2 & 3 & 2 & 1 & 3 & 2 & 1 & 3 & 2 & 1 \\
\hline 22 & 3 & 2 & 1 & 3 & 1 & 3 & 2 & 2 & 1 & 3 & 3 & 2 & 1 \\
\hline 23 & 3 & 2 & 1 & 3 & 2 & 1 & 3 & 3 & 2 & 1 & 1 & 3 & 2 \\
\hline 24 & 3 & 2 & 1 & 3 & 3 & 2 & 1 & 1 & 3 & 2 & 2 & 1 & 3 \\
\hline 25 & 3 & 3 & 2 & 1 & 1 & 3 & 2 & 3 & 2 & 1 & 2 & 1 & 3 \\
\hline 26 & 3 & 3 & 2 & 1 & 2 & 1 & 3 & 1 & 3 & 2 & 3 & 2 & 1 \\
\hline 27 & 3 & 3 & 2 & 1 & 3 & 2 & 1 & 2 & 1 & 3 & 1 & 3 & 2 \\
\hline
\end{tabular}

assigned to speed $(B)$, the fifth column is assigned to time $(C)$, and six columns are assigned to the two-way interactions of the first three factors, while the remaining three columns are for error terms. In the present experimentation each test is repeated three times. Two quality characteristics were measured by a multitribotester machine and then integrated by the grey relational analysis [25] with considerations of correlation and weighting. The optimal process parameters are determined by the response table and response graph of the grey relational grade. Figure 1 shows the flowchart of the experiment design. The optimal combinations of the process parameters attained by the data analysis can be used to predict the optimal grey relational grade and the corresponding confidence interval. The predicted grey relational grade of 


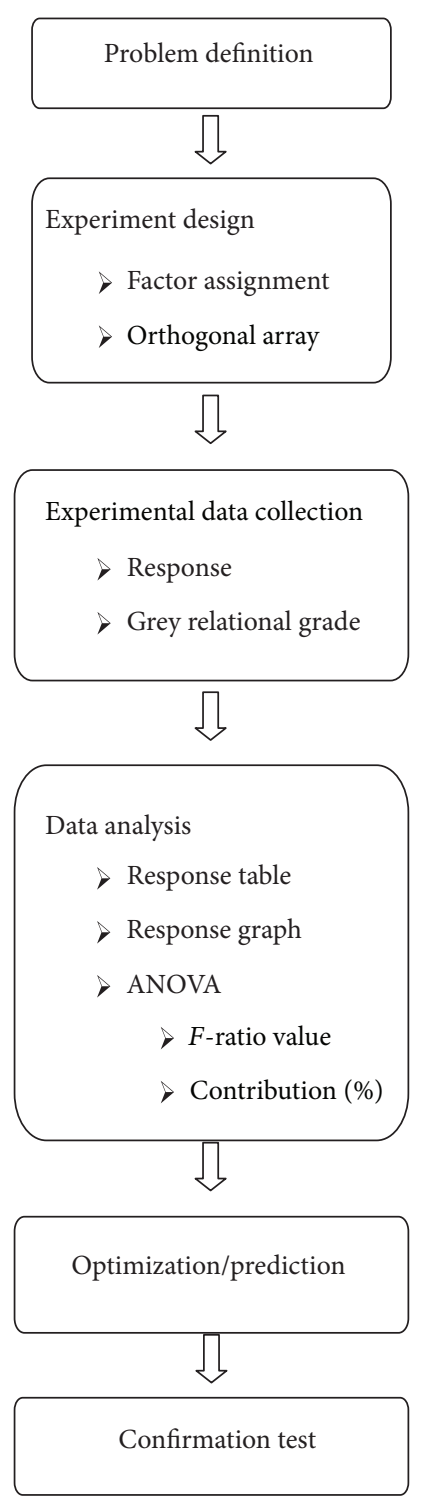

FIGURE 1: Flowchart of design of experiment.

individual quality characteristic served as the criterion for comparison with the confirmation experiment. The final step of the experiment design is to verify the improvement of the quality characteristics using the optimal parameters obtained by the grey relational analysis.

2.5. Tribological Testing. Wear depth and friction coefficient of heat-treated Ni-P-W coated specimens are measured using a multitribotester with block on roller configuration (DUCOM, TR-25) under nonlubricated condition at an ambient temperature of about $25^{\circ} \mathrm{C}$ and relative humidity of about $85 \%$. The Ni-P-W coated specimens serve as test specimens which are held horizontally against a rotating roller of $50 \mathrm{~mm}$ diameter $\times 20 \mathrm{~mm}$ thickness. The schematic diagram of the tribotester apparatus is described elsewhere [26]. The photograph of the arrangement of the specimen against roller is given in Figure 2. The steel roller is coated

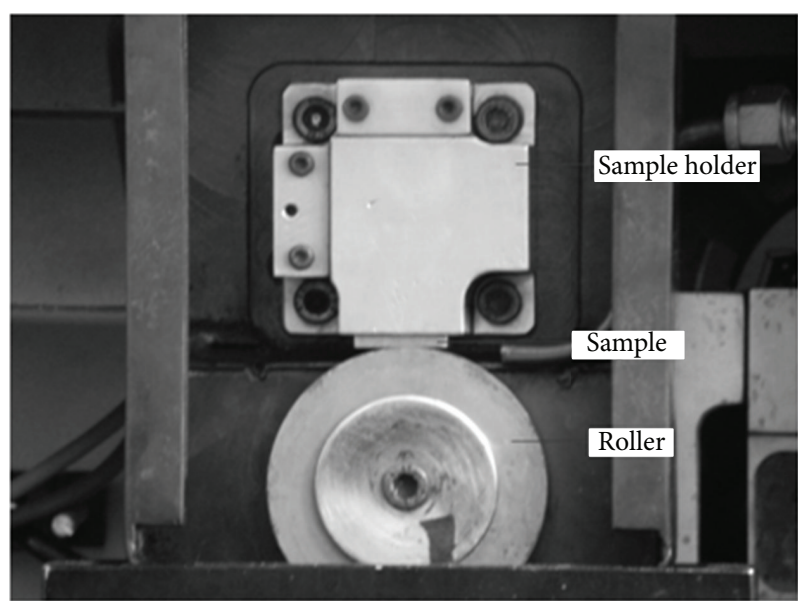

FIGURE 2: Photograph of the arrangement of the specimen against roller.

with titanium nitride of hardness $85 \mathrm{HRc}$, which is higher than the hardness of the Ni-P-W coated specimen $(42 \mathrm{HRc})$ in order to ensure that the wear will take place only in the test specimens. Weights are placed on the loading platform which is attached at one end of a 1:5 ratio loading lever so that the actual applied load at the contact becomes 5 times the weight placed on the loading pan. The loading lever is pivoted near the normal load sensor and carries a counter weight at one end while at the other end the loading pan is suspended for placing the dead weights. The frictional force is measured by a frictional force sensor that uses a beam type load cell of $1000 \mathrm{~N}$ capacity. Wear is measured in terms of displacement with the help of linear voltage resistance transducer. It is worth noting that, in general, wear is measured in terms of wear volume or mass loss. But, in the present case, wear is expressed in terms of displacement or wear depth. Hence, to ensure that the wear measurements are accurate, the displacement results for wear are compared with the weight loss of the specimens and almost linear relationship is observed between the two for the range of test parameters considered in the present study. The speed of the roller and the duration of tests can be controlled via a computer attached to the tribotester. The values of the tribological test parameters for friction and wear tests are shown in Table 2. The experimental results for coefficient of friction and wear depth are shown in Table 4.

2.6. Structural Aspects and Composition Study. The characterization of the coating is essential to make sure that the coating is properly developed. In the present study, surface morphology of the coating is observed through scanning electron microscope (SEM) (FEI Quanta 200) in order to analyse the microstructure of the heat-treated deposits. SEM is also done after the wear testing to see the pattern of the sliding tracks in order to predict the wear mechanism. Energy dispersive X-ray analysis (EDAX Corporation) is performed to determine the composition of the coating in terms of the weight percentages of nickel, phosphorous, and tungsten. The different precipitated phases of heat-treated specimen are 
TABLE 4: Experimental values of coefficient of friction and wear depth.

\begin{tabular}{|c|c|c|}
\hline Exp. no. & $\mathrm{COF}$ & Wear $(\mu \mathrm{m})$ \\
\hline 1 & 0.4785 & 6.2982 \\
\hline 2 & 0.46276 & 7.1545 \\
\hline 3 & 0.48203 & 8.055 \\
\hline 4 & 0.39932 & 7.258 \\
\hline 5 & 0.44238 & 8.0496 \\
\hline 6 & 0.44215 & 9.0692 \\
\hline 7 & 0.52605 & 14.164 \\
\hline 8 & 0.54982 & 16.7608 \\
\hline 9 & 0.55751 & 22.0726 \\
\hline 10 & 0.52421 & 10.3106 \\
\hline 11 & 0.55811 & 11.789 \\
\hline 12 & 0.53767 & 14.6806 \\
\hline 13 & 0.48066 & 6.9654 \\
\hline 14 & 0.51542 & 11.114 \\
\hline 15 & 0.56446 & 15.4086 \\
\hline 16 & 0.40976 & 14.8242 \\
\hline 17 & 0.45888 & 17.8212 \\
\hline 18 & 0.44027 & 20.0548 \\
\hline 19 & 0.40823 & 19.9342 \\
\hline 20 & 0.46926 & 24.2414 \\
\hline 21 & 0.50418 & 24.8034 \\
\hline 22 & 0.47685 & 11.6952 \\
\hline 23 & 0.51858 & 14.6608 \\
\hline 24 & 0.47967 & 16.5214 \\
\hline 25 & 0.42368 & 16.7828 \\
\hline 26 & 0.52806 & 20.4608 \\
\hline 27 & 0.46618 & 24.7724 \\
\hline
\end{tabular}

identified with the help of X-ray diffraction (XRD) analysis (Rigaku, Ultima III).

\section{Result and Discussion}

As discussed earlier, wear depth and friction coefficient of 27 heat-treated Ni-P-W coated specimens are measured using a multitribotester and the experimental values are shown in Table 4 . The variation of coefficient of friction with sliding time can be better understood from Figure 3. It is observed that at the initial stage coefficient of friction increases rapidly; then for the rest of the time it remains more or less constant. Now to combine the effect of both responses, that is, wear depth and friction coefficient, the grey relational analysis is performed. The following methodology is used to obtain the grey relational grade.

3.1. Normalizing the Responses. The normalization procedure involves the aim of the experiment, whether the response variables are to be minimized or maximized. Here both wear depth and coefficient of friction $(\mathrm{COF})$ are to be minimized

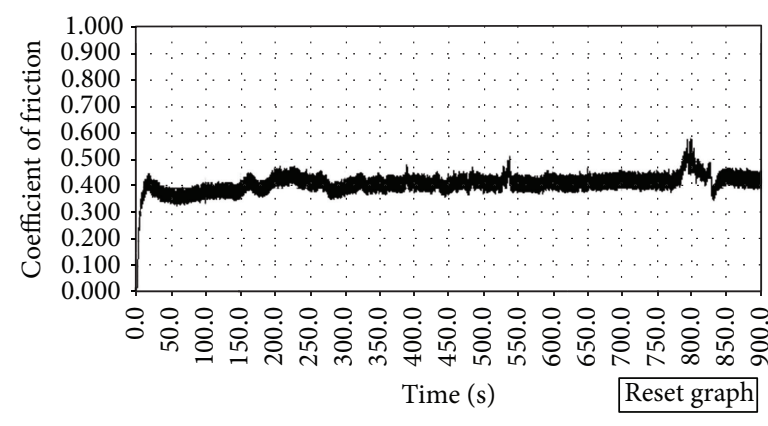

FIGURE 3: Variation of coefficient of friction with sliding time.

so the following lower the better formula is used to normalize both responses:

$$
x_{i}(k)=\frac{\max y_{i}(k)-y_{i}(k)}{\max y_{i}(k)-\min y_{i}(k)},
$$

where $x_{i}(k)$ is the normalized value, $\min y_{i}(k)$ is the smallest value of $y_{i}(k)$ for the $k$ th response, and max $y_{i}(k)$ is the largest value of $y_{i}(k)$ for the $k$ th response, with $k$ being 1 (COF) and 2 (wear depth). Larger normalized results correspond to the better performance and the best normalized result should be equal to 1.

3.2. Grey Relational Coefficients. Grey relational coefficients are calculated to express the relationship between the ideal (best $=1$ ) and the actual experimental results. From the normalized values, the grey relational coefficient is calculated using the following equation:

$$
\xi_{i}(k)=\frac{\Delta_{\min }+r \Delta_{\max }}{\Delta_{0 i}(k)+r \Delta_{\max }},
$$

where $\Delta_{0 i}=\left\|x_{0}(k)-x_{i}(k)\right\|$ is the difference of the absolute value between $x_{0}(k)$ and $x_{i}(k)$ and $\Delta_{\min }$ and $\Delta_{\max }$ are, respectively, the minimum and maximum values of the absolute differences $\left(\Delta_{0 i}\right)$ of all comparing sequences. Here, $r$ is the distinguishing coefficient which is used to adjust the difference of the relational coefficient, usually $r \in\{0,1\}$ [25]. The distinguishing coefficient weakens the effect of $\Delta_{\max }$ when it gets too big, enlarging the different significance of the relational coefficient. The suggested value of the distinguishing coefficient, $r$, is 0.5 , due to the moderate distinguishing effects and good stability of outcomes. Therefore, $r$ is adopted as 0.5 for further analysis in the present case. All the normalized values and grey relational coefficients are shown in Table 5.

3.3. Generation of Grey Relational Grade and Ordering. The overall multiple response characteristics evaluation is based on grey relational grade which is calculated from the data obtained in the previous step using the following equation:

$$
\gamma_{i}=\frac{1}{n} \sum_{k=i}^{n} \xi_{i}(k)
$$


TABLE 5: Grey relational analysis for friction coefficient and wear depth.

\begin{tabular}{|c|c|c|c|c|c|c|}
\hline \multirow{2}{*}{ Exp. no. } & \multicolumn{2}{|c|}{ Normalized Data } & \multicolumn{2}{|c|}{$\Delta$ Values } & \multicolumn{2}{|c|}{ Grey relational coefficient } \\
\hline & Cof & Wear & Cof & Wear & Cof & Wear \\
\hline 1 & 0.521 & 1.000 & 0.479 & 0.000 & 0.510 & 1.000 \\
\hline 2 & 0.616 & 0.954 & 0.384 & 0.046 & 0.566 & 0.915 \\
\hline 3 & 0.499 & 0.905 & 0.501 & 0.095 & 0.500 & 0.840 \\
\hline 4 & 1.000 & 0.948 & 0.000 & 0.052 & 1.000 & 0.906 \\
\hline 5 & 0.739 & 0.905 & 0.261 & 0.095 & 0.657 & 0.841 \\
\hline 6 & 0.741 & 0.850 & 0.259 & 0.150 & 0.658 & 0.770 \\
\hline 7 & 0.233 & 0.575 & 0.767 & 0.425 & 0.395 & 0.541 \\
\hline 8 & 0.089 & 0.435 & 0.911 & 0.565 & 0.354 & 0.469 \\
\hline 9 & 0.042 & 0.148 & 0.958 & 0.852 & 0.343 & 0.370 \\
\hline 10 & 0.244 & 0.783 & 0.756 & 0.217 & 0.398 & 0.698 \\
\hline 11 & 0.038 & 0.703 & 0.962 & 0.297 & 0.342 & 0.628 \\
\hline 12 & 0.162 & 0.547 & 0.838 & 0.453 & 0.374 & 0.525 \\
\hline 13 & 0.507 & 0.964 & 0.493 & 0.036 & 0.504 & 0.933 \\
\hline 14 & 0.297 & 0.740 & 0.703 & 0.260 & 0.416 & 0.658 \\
\hline 15 & 0.000 & 0.508 & 1.000 & 0.492 & 0.333 & 0.504 \\
\hline 16 & 0.937 & 0.539 & 0.063 & 0.461 & 0.888 & 0.520 \\
\hline 17 & 0.639 & 0.377 & 0.361 & 0.623 & 0.581 & 0.445 \\
\hline 18 & 0.752 & 0.257 & 0.248 & 0.743 & 0.668 & 0.402 \\
\hline 19 & 0.946 & 0.263 & 0.054 & 0.737 & 0.903 & 0.404 \\
\hline 20 & 0.576 & 0.030 & 0.424 & 0.970 & 0.541 & 0.340 \\
\hline 21 & 0.365 & 0.000 & 0.635 & 1.000 & 0.441 & 0.333 \\
\hline 22 & 0.531 & 0.708 & 0.469 & 0.292 & 0.516 & 0.632 \\
\hline 23 & 0.278 & 0.548 & 0.722 & 0.452 & 0.409 & 0.525 \\
\hline 24 & 0.513 & 0.448 & 0.487 & 0.552 & 0.507 & 0.475 \\
\hline 25 & 0.852 & 0.433 & 0.148 & 0.567 & 0.772 & 0.469 \\
\hline 26 & 0.220 & 0.235 & 0.780 & 0.765 & 0.391 & 0.395 \\
\hline 27 & 0.595 & 0.002 & 0.405 & 0.998 & 0.553 & 0.334 \\
\hline
\end{tabular}

where $n$ is the number of process responses. Finally, the grades are considered for the optimization of multi-response parameter design problem. The value of grey relational grade is shown in Table 6.

3.4. Analysis of Grey Relational Grade. The grey relational grade serves as the overall performance index. Thus, the higher value of grey relational grade indicates better performance. Now to find out the effect of each level of each individual factor on the grey relational grade a response table of grey relational grade is generated which is shown in Table 7. This is possible because the experimental design is orthogonal and the effect of each design parameter at different levels is separable. For example, the mean of grey relational grade for design factor $\mathrm{A}$ at level 1 can be calculated by taking the average of the grey relational grade for the experiments 1-9, because for the first 9 experiments in the
OA each row of the column assigned to A contains level 1. The mean of the grey relational grade for each level of each of the design parameters can be computed in a similar manner. In addition, the total mean of the grey relational grade of the twenty-seven experiments is also calculated, as shown in Table 7. The response table also contains ranks based on the delta values. The delta value is calculated by subtracting the lowest value from the largest from among the values in each column. Basically, a design factor with a large difference in the grey relational grade from one factor setting to another indicates that the factor or design parameter is a significant contributor to the achievement of the performance characteristic. From the response table it is found that the sequence of significance of the design parameters is time, load, and speed, respectively, in controlling the friction and wear characteristics of Ni-P-W coatings. The main effect plot and interaction plots are shown in Figures 4 and 5, respectively. The main effect plot gives a rough idea about the relative 
TABLE 6: Grey relational grade and its order.

\begin{tabular}{|c|c|c|}
\hline Sl. no. & Grey relational grade & Order \\
\hline 1 & 0.75524 & 2 \\
\hline 2 & 0.74040 & 4 \\
\hline 3 & 0.67000 & 8 \\
\hline 4 & 0.95301 & 1 \\
\hline 5 & 0.74904 & 3 \\
\hline 6 & 0.71399 & 6 \\
\hline 7 & 0.46751 & 18 \\
\hline 8 & 0.41179 & 24 \\
\hline 9 & 0.35633 & 27 \\
\hline 10 & 0.54776 & 12 \\
\hline 11 & 0.48484 & 17 \\
\hline 12 & 0.44921 & 20 \\
\hline 13 & 0.71825 & 5 \\
\hline 14 & 0.53665 & 13 \\
\hline 15 & 0.41860 & 23 \\
\hline 16 & 0.70409 & 7 \\
\hline 17 & 0.51315 & 15 \\
\hline 18 & 0.53530 & 14 \\
\hline 19 & 0.65342 & 9 \\
\hline 20 & 0.44081 & 22 \\
\hline 21 & 0.38694 & 26 \\
\hline 22 & 0.57367 & 11 \\
\hline 23 & 0.46718 & 19 \\
\hline 24 & 0.49095 & 16 \\
\hline 25 & 0.62049 & 10 \\
\hline 26 & 0.39295 & 25 \\
\hline 27 & 0.44314 & 21 \\
\hline
\end{tabular}

TABLE 7: Response table for grey relational grade.

\begin{tabular}{lccc}
\hline Level & Load & Speed & Time \\
\hline 1 & 0.6464 & 0.5698 & 0.6659 \\
2 & 0.5453 & 0.6246 & 0.5263 \\
3 & 0.4966 & 0.4939 & 0.4961 \\
Delta & 0.1498 & 0.1307 & 0.1699 \\
Rank & 2 & 3 & 1 \\
\hline
\end{tabular}

Total mean grey relational grade $=0.562767$.

significance of the parameters on the system response. If the plot for a particular parameter has the highest inclination, then that parameter has the maximum significance, whereas the plot which is near horizontal has no significance. So from Figure 4 it is clear that time $(C)$ and load $(A)$ have the most significant effect on the tribological behaviour of Ni-P-W coating whereas speed $(B)$ has little significance. The plot also shows that with the increase of load and time separately the grey relational grades decrease, and hence coefficient of friction and wear rate increase. Thus, at lower levels of load and time, coefficient of friction and wear characteristics of heat-treated Ni-P-W coating show better result. This observation is in good agreement with earlier studies [11, 12]. But, with the increase of speed from level 1 to level 2, the grey relational grade increases and reaches the maximum value at level 2 then it decreases to level 3. It means that the tribological characteristics, that is, coefficient of friction and wear characteristics, show a better result at middle level of speed within the range of speeds considered in the present investigation. But the most interesting observation is the behavior of tribological characteristics when two factors are varying simultaneously. This can be understood from the interaction plots. The influence of interaction between two parameters is determined on the basis of intersection of lines in the interaction plots. From Figure 5 it can be observed that the interaction between load $(A)$ and speed $(B)$ has the most significant influence on the tribological characteristics. The main effect plot also gives the optimal combination of design parameters for minimum friction and wear. The larger the grey relation grade is, the closer the product quality will be to the ideal value. Hence, the optimal combination of parameters is found to be A1B2C1.

3.5. Analysis of Variance (ANOVA). The significance of any parameter is dependent on the variance ratio. The variance ratio is commonly called the F-statistics which may be defined as the variance of the factor divided by the error variance. The variance of each factor is determined by the sum of the square of each trial sum result involving the factor, divided by the degrees of freedom of the factor. The analysis of variance [27] is performed using MINITAB [28] software. The tables for various significance levels and different degrees of freedom are available in most handbooks of statistics. If the calculated $F$-value is larger than the tabulated $F$-value, then the factor is considered as a significant factor. The ANOVA results shown in Table 8 revealed that all the individual design factors have the significant influence and among the interactions, load versus speed has significant influence in controlling the tribological properties. The ANOVA table also shows the percentage contribution of the individual factors and their interactions in controlling the tribological behaviour of Ni-P-W coating.

3.6. Microstructure Analysis. Figure 6 shows the SEM micrograph of Ni-P-W coatings heat-treated at $400^{\circ} \mathrm{C}$. It is clear that the heat-treated coating consists of large globules without any porosity and mainly coarse grained structure is observed. Figure 7 shows the SEM micrograph of worn surfaces. From the images it is clear that the load is taken by some of the peak globules where the other peaks remain intact. The wear mechanism is generally mild adhesive in nature because no plowing effect or abrasive particle is observed on the worn surface. Material removal in patches is noticed in SEM images. Moreover, the amount of weight loss of the specimens due to wear corroborates the mild adhesive wear to be predominant. Figure 8 shows the EDX spectra of the coated 


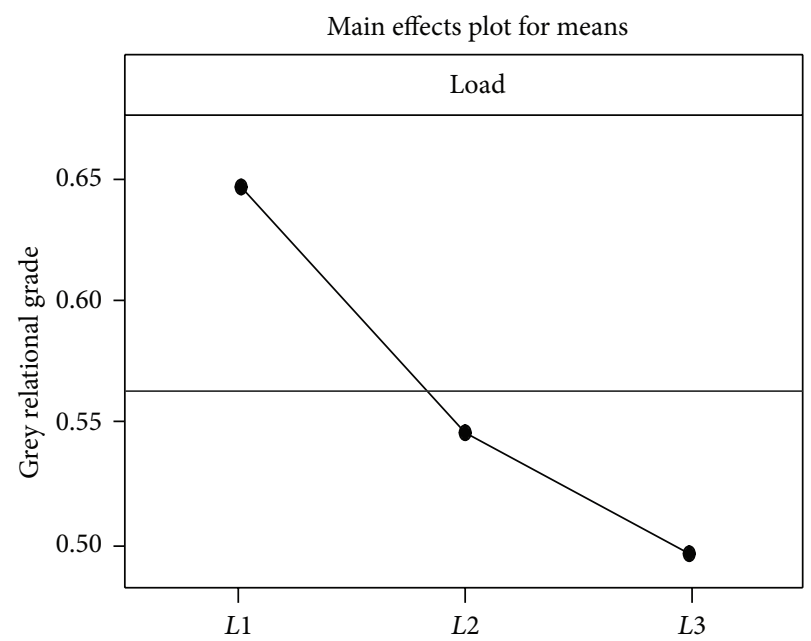

(a)

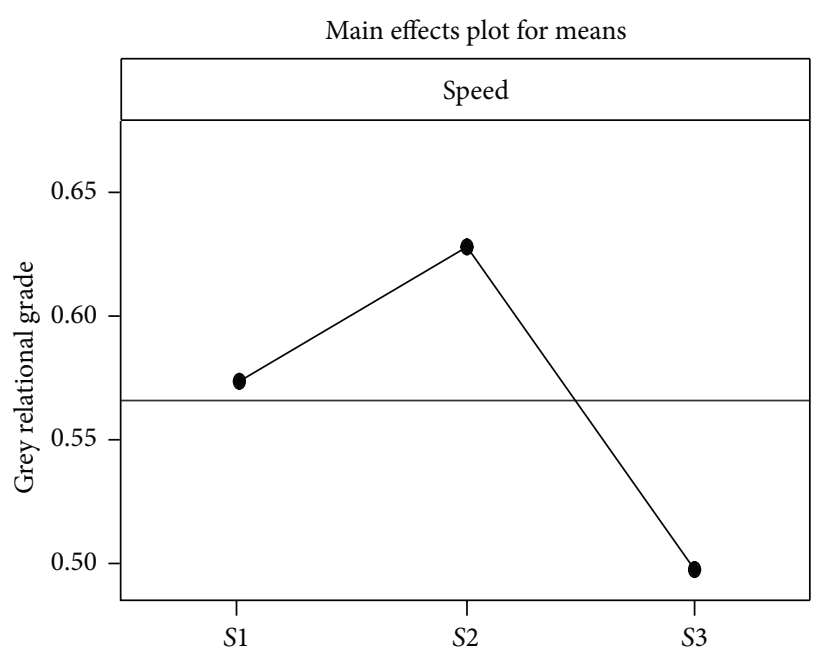

(b)

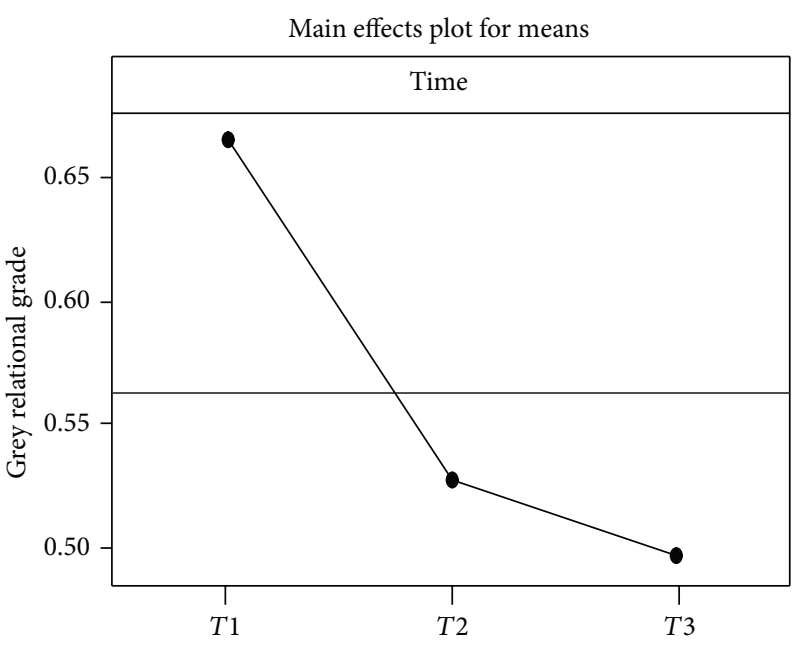

(c)

FIgURE 4: Main effect plot of mean grey relational grade.

surface. Tungsten content in terms of weight percentages is found to be in the range of $5-6 \%$ and phosphorus content is in the range of $8-10 \%$, while the remaining is mostly nickel. Figure 9 shows the XRD plot of the coatings at heat-treated condition. From the figure it is seen that the heat-treated coating has broad crystalline peak and produced crystalline phases. The major crystalline peaks are $\mathrm{Ni}-\mathrm{W}$ and $\mathrm{Ni}_{3} \mathrm{P}$.

\section{Validation Study}

Once the optimal level of design parameters has been found out, the final step is to verify the improvement of the performance characteristic using the optimal level of the process parameters. The estimated grey relational grade $\hat{\eta}$ using the optimal level of the process parameters can be calculated as

$$
\widehat{\eta}=\eta_{m}+\sum_{i=1}^{o}\left(\bar{\eta}_{i}-\eta_{m}\right)
$$

where $\eta_{m}$ is the total mean grey relational grade, $\bar{\eta}_{i}$ is the mean grey relational grade at the optimal process parameter level, and $o$ is the number of the main design process parameters that significantly affect the tribological characteristics of $\mathrm{Ni}$ $\mathrm{P}-\mathrm{W}$ coating. Table 9 shows the comparison of the estimated grey relational grade with the actual grey relational grade using the optimal parameters. The improvement of grey relational grade from initial to optimal condition is 0.416358 , which is about $78 \%$ of the mean grey relational grade, and it is a significant improvement.

\section{Conclusion}

Ni-P-W coatings are developed on mild steel substrates by electroless deposition and tested for friction and wear behavior in a multitribotester using block on roller configuration under dry conditions. The design parameters (load, speed, and time) are optimized in order to minimize friction and wear of the coatings. Grey relational analysis is successfully 


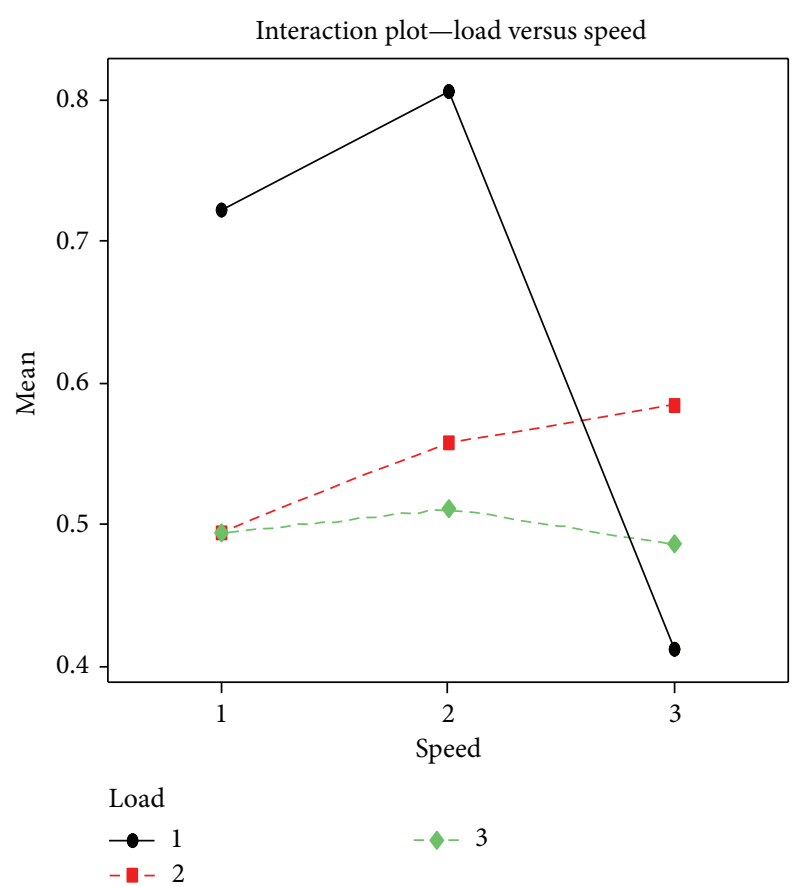

(a)

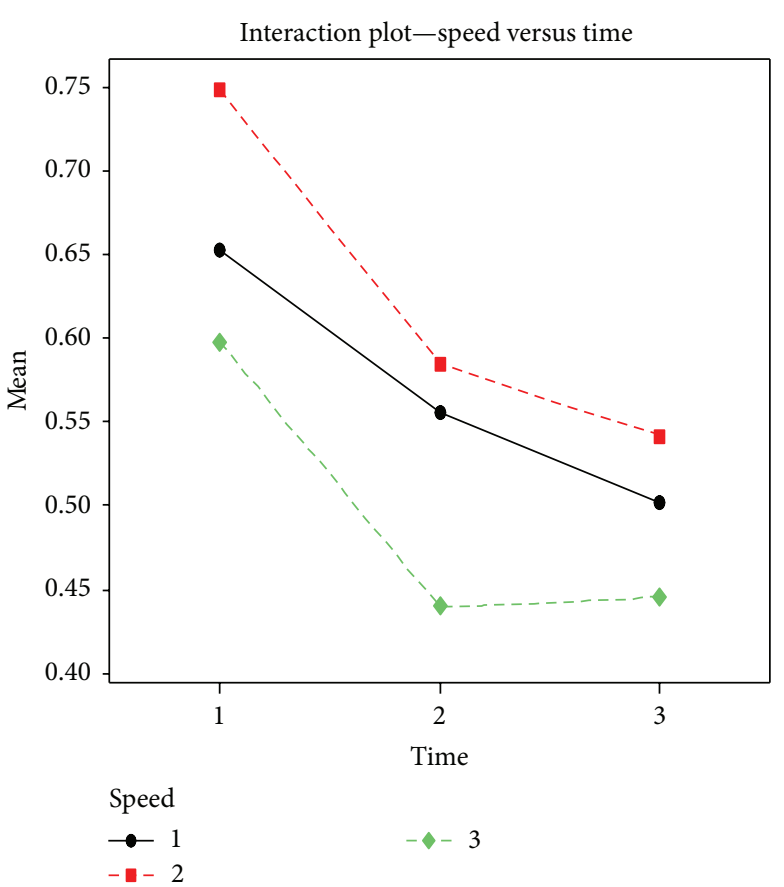

(b)

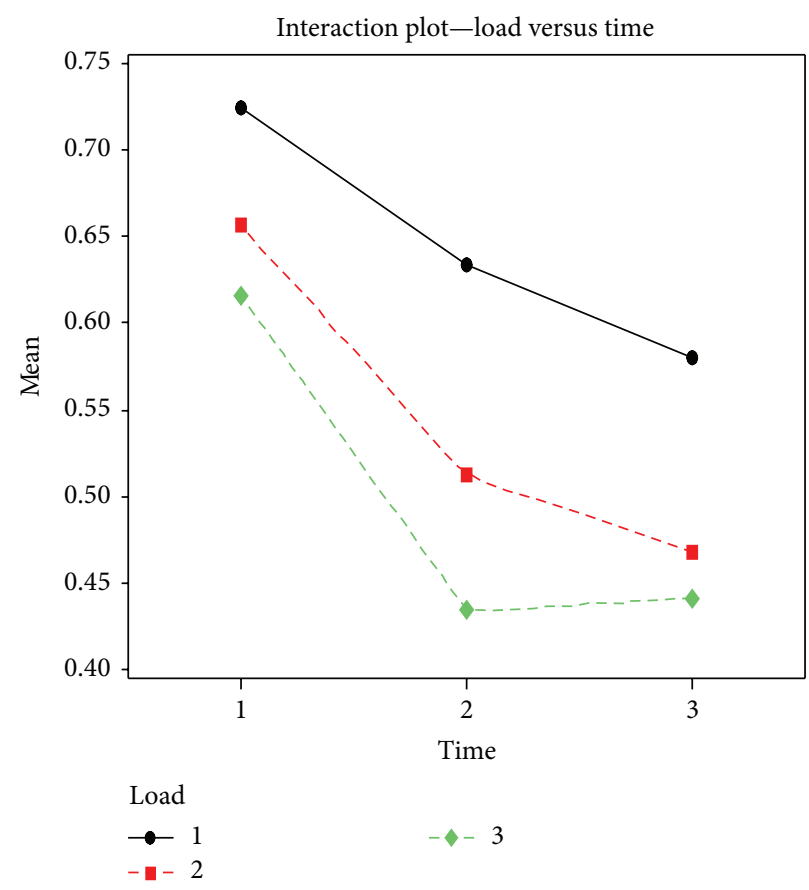

(c)

FIGURE 5: Interaction plots for mean grey relational grade: (a) load versus speed, (b) speed versus time, and (c) load versus time.

employed in conjunction with Taguchi design of experiments to optimize this multiple response problem. The optimal combination of coating parameters is obtained as A1B2C1, that is, the lowest levels of load and time and the middle level of speed. ANOVA result indicates that all the individual design factors have the significant influence and among the interactions, load versus speed has significant influence in controlling the tribological properties. From the EDX analysis it is clear that the coating is pure ternary and consists of nickel, phosphorous, and tungsten. The XRD plots reveal that the coating is a mixture of amorphous and crystalline structure with $\mathrm{Ni}-\mathrm{W}$ and $\mathrm{Ni}_{3} \mathrm{P}$ as major compounds after heat 


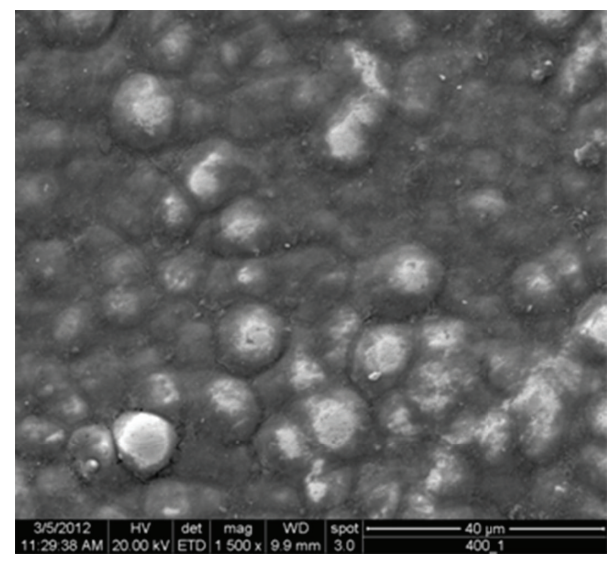

FIGURE 6: SEM image of Ni-P-W coatings annealed at $400^{\circ} \mathrm{C}$.

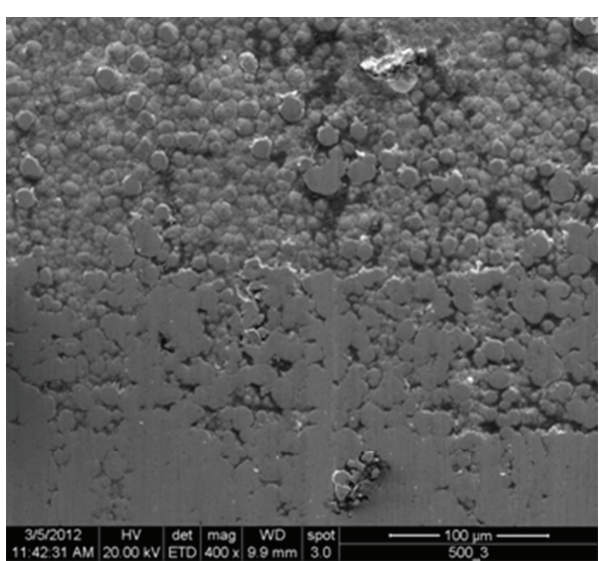

(a)

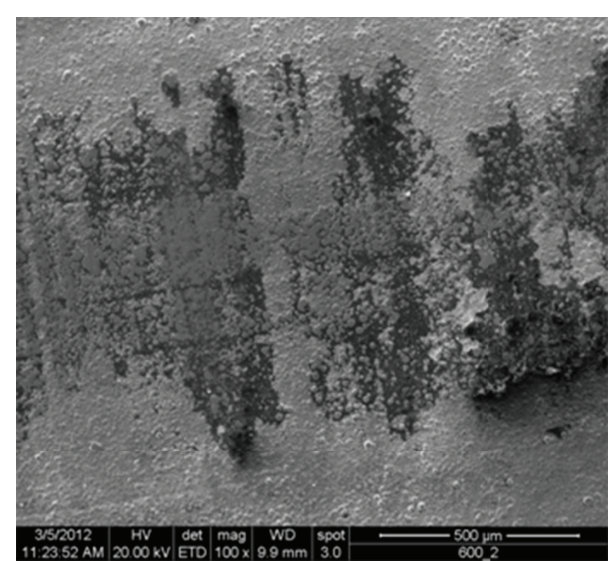

(b)

FIGURE 7: SEM image of (a) worn surface and (b) wear track.

TABLE 8: Results of ANOVA for grey relational grade.

\begin{tabular}{|c|c|c|c|c|c|}
\hline Source & Degree of freedom & Sum of square & Mean of square & $F$-ratio & $\%$ contribution \\
\hline Load & 2 & 0.105025 & 0.052513 & $14.67^{*}$ & 18.51 \\
\hline Speed & 2 & 0.077586 & 0.038793 & $10.84^{*}$ & 13.67 \\
\hline Time & 2 & 0.147818 & 0.073909 & $20.65^{*}$ & 26.05 \\
\hline Load $*$ speed & 4 & 0.194203 & 0.048551 & $13.57^{*}$ & 34.23 \\
\hline Load $*$ time & 4 & 0.007265 & 0.001816 & 0.51 & 1.28 \\
\hline Speed $*$ time & 4 & 0.006837 & 0.001709 & 0.48 & 1.21 \\
\hline Error & 8 & 0.028627 & 0.003578 & & 5.05 \\
\hline Total & 26 & 0.567361 & & & 100 \\
\hline
\end{tabular}

${ }^{*}$ Significant at $99 \%$ confidence level.

TABLE 9: Results of confirmation test.

\begin{tabular}{|c|c|c|c|}
\hline & \multirow{2}{*}{ Initial parameter combination } & \multicolumn{2}{|c|}{ Optimum parameter combination } \\
\hline & & Prediction & Experimentation \\
\hline Setting level & $\mathrm{A} 2 \mathrm{~B} 2 \mathrm{C} 2$ & \multicolumn{2}{|c|}{$\mathrm{A} 1 \mathrm{~B} 2 \mathrm{C} 1$} \\
\hline $\mathrm{COF}$ & 0.51642 & & 0.39932 \\
\hline Wear depth & 11.114 & & 7.258 \\
\hline Grade & 0.53665 & 0.811367 & 0.953008 \\
\hline
\end{tabular}




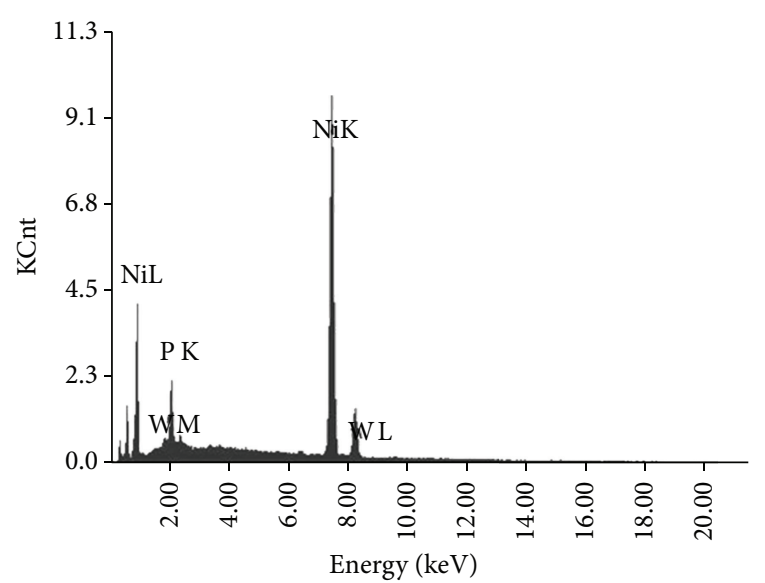

FIGURE 8: EDX spectra of Ni-P-W coated surface.

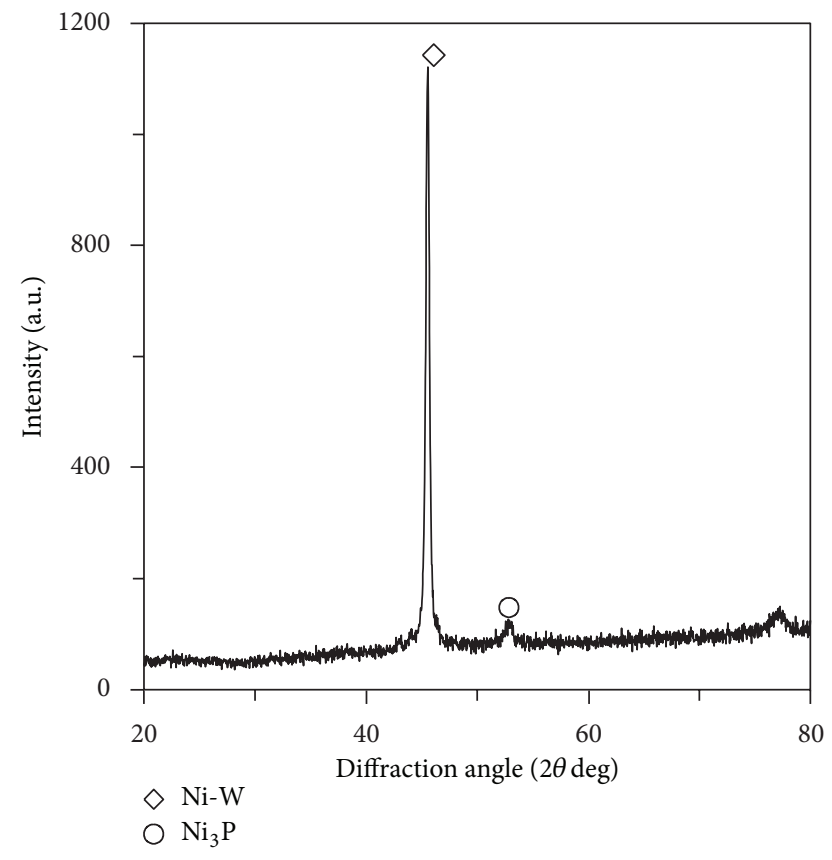

FIGURE 9: XRD plots of Ni-P-W coatings.

treatment. From the surface morphology captured by SEM it is seen that there are many globular particles on the surface of the substrate with no surface damage. Also the coating is dense and with low porosity. The pattern of the sliding tracks showed that mild adhesive wear is the predominant wear mechanism.

\section{References}

[1] A. Brenner and G. E. Riddell, "Nickel coating on steel by chemical reduction," Journal of Research of National Bureau of Standards, vol. 37, no. 1, pp. 31-34, 1946.

[2] G. O. Mallory and J. B. Hadju, Electroless Plating: Fundamentals and Applications, AESF, Orlando, Fla, USA, 1991.

[3] W. Riedel, Electroless Plating, ASM International, Materials Park, Ohio, USA, 1991.
[4] P. Sahoo and S. K. Das, "Tribology of electroless nickel coatings-a review," Materials and Design, vol. 32, no. 4, pp. 1760-1775, 2011.

[5] P. Sahoo, "Wear behaviour of electroless Ni-P coatings and optimization of process parameters using Taguchi method," Materials and Design, vol. 30, no. 4, pp. 1341-1349, 2009.

[6] S. K. Das and P. Sahoo, "Tribological characteristics of electroless Ni-B coating and optimization of coating parameters using Taguchi based grey relational analysis," Materials and Design, vol. 32 , no. 4 , pp. 2228-2238, 2011.

[7] S.-K. Tien, J.-G. Duh, and Y. I. Chen, "The influence of thermal treatment on the microstructure and hardness in electroless $\mathrm{Ni}$ P-W deposit," Thin Solid Films, vol. 469-470, pp. 333-338, 2004.

[8] Y.-J. Hu, T.-X. Wang, J.-L. Meng, and Q.-Y. Rao, "Structure and phase transformation behaviour of electroless Ni-W-P on aluminium alloy," Surface and Coatings Technology, vol. 201, no. 3-4, pp. 988-992, 2006.

[9] R. C. Agarwala and V. Agarwala, "Electroless alloy/composite coatings: a review," Sadhana, vol. 28, pp. 3475-3493, 2003.

[10] F. Pearlstein, R. F. Weightman, and R. Wick, MetalFinishing, vol. 61, pp. 77-81, 1963.

[11] M. Palaniappa and S. K. Seshadri, "Friction and wear behavior of electroless Ni-P and Ni-W-P alloy coatings," Wear, vol. 265, no. 5-6, pp. 735-740, 2008.

[12] H. Liu, R. X. Guo, and Z. Liu, "Effects of laser nanocrystallisation on the wear behaviour of electroless Ni-W-P coatings," Surface \& Coatings Technology, vol. 219, pp. 31-41, 2013.

[13] F.-B. Wu, Y.-I. Chen, P.-J. Peng, Y.-Y. Tsai, and J.-G. Duh, "Fabrication, thermal stability and microhardness of sputtered Ni-P-W coating," Surface and Coatings Technology, vol. 150, no. 2-3, pp. 232-238, 2002.

[14] Y.-Y. Tsai, F.-B. Wu, Y.-I. Chen, P.-J. Peng, J.-G. Duh, and S.-Y. Tsai, "Thermal stability and mechanical properties of Ni-W-P electroless deposits," Surface and Coatings Technology, vol. 146147, pp. 146-147, 2001.

[15] F. B. Wu, S. K. Tien, W. Y. Chen, and J. G. Duh, "Microstructure evaluation and strengthening mechanism of Ni-P-W alloy coatings," Surface and Coatings Technology, vol. 177-178, pp. 312316, 2004.

[16] S.-K. Tien and J.-G. Duh, "Thermal reliability of electroless NiP-W coating during the aging treatment," Thin Solid Films, vol. 469-470, pp. 268-273, 2004.

[17] W.-Y. Chen, S.-K. Tien, F.-B. Wu, and J.-G. Duh, "Crystallization behaviors and microhardness of sputtered Ni-P, Ni-P-Cr and Ni-P-W deposits on tool steel," Surface and Coatings Technology, vol. 182, no. 1, pp. 85-91, 2004.

[18] J. N. Balaraju and K. S. Rajam, "Electroless deposition of Ni$\mathrm{Cu}-\mathrm{P}, \mathrm{Ni}-\mathrm{W}-\mathrm{P}$ and Ni-W-Cu-P alloys," Surface and Coatings Technology, vol. 195, no. 2-3, pp. 154-161, 2005.

[19] J. N. Balaraju, C. Anandan, and K. S. Rajam, "Influence of codeposition of copper on the structure and morphology of electroless Ni-W-P alloys from sulphate- and chloride-based baths," Surface and Coatings Technology, vol. 200, no. 12-13, pp. 3675-3681, 2006.

[20] C. Xiao-ming, L. I. Guang-yu, and L. Jian-she, "Deposition of electroless Ni-P/Ni-W-P duplex coatings on AZ91D magnesium alloy," Transactions of Nonferrous Metals Society of China, vol. 18, no. 1, pp. s323-s328, 2008.

[21] H. Liu, R.-X. Guo, Y. Zong, B.-Q. He, and Z. Liu, "Comparative study of microstructure and corrosion resistance of electroless 
Ni-W-P coatings treated by laser and furnace-annealing," Transactions of Nonferrous Metals Society of China, vol. 20, no. 6, pp. 1024-1031, 2010.

[22] J. N. Balaraju, S. M. Jahan, and K. S. Rajam, "Studies on autocatalytic deposition of ternary Ni-W-P alloys using nickel sulphamate bath," Surface and Coatings Technology, vol. 201, no. 3-4, pp. 507-512, 2006.

[23] J. N. Balaraju, S. Millath Jahan, C. Anandan, and K. S. Rajam, "Studies on electroless Ni-W-P and Ni-W-Cu-P alloy coatings using chloride-based bath," Surface and Coatings Technology, vol. 200, no. 16-17, pp. 4885-4890, 2006.

[24] R. K. Roy, A Primer on the Taguchi Method, Society of Manufacturing Engineers, Dearborn, Mich, USA, 1990.

[25] J. Deng, "Nucleus less-data series grey modeling," Journal of Grey System, vol. 1, no. 1, pp. 1-24, 1989.

[26] S. K. Das and P. Sahoo, "Wear performance optimization of electroless Ni-B coating using Taguchi design of experiments," Tribology in Industry, vol. 32, no. 4, pp. 17-27, 2010.

[27] D. C. Montgomery, Design and Analysis of Experiments, John Wiley \& Sons, New York, NY, USA, 2001.

[28] Minitab User Manual (Release 13. 2). Making Data Analysis Easier, MINITAB, State College, Pa, USA, 2001. 

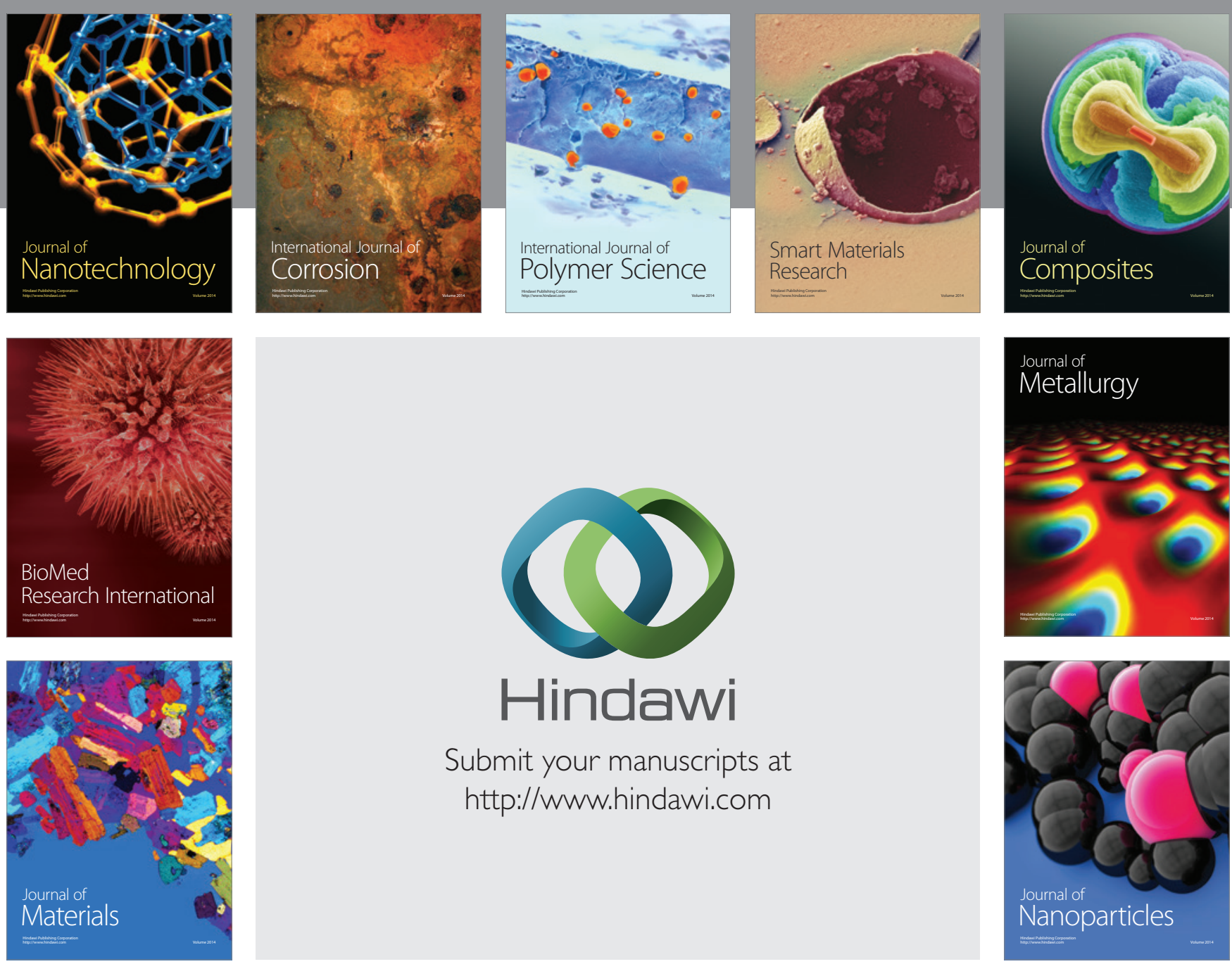

Submit your manuscripts at http://www.hindawi.com
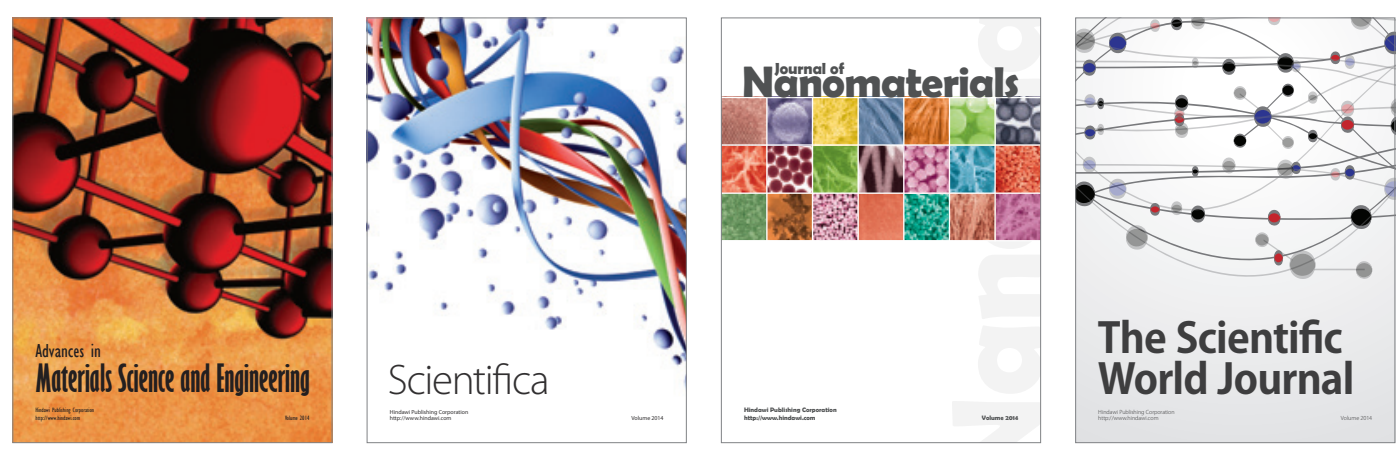

\section{The Scientific World Journal}
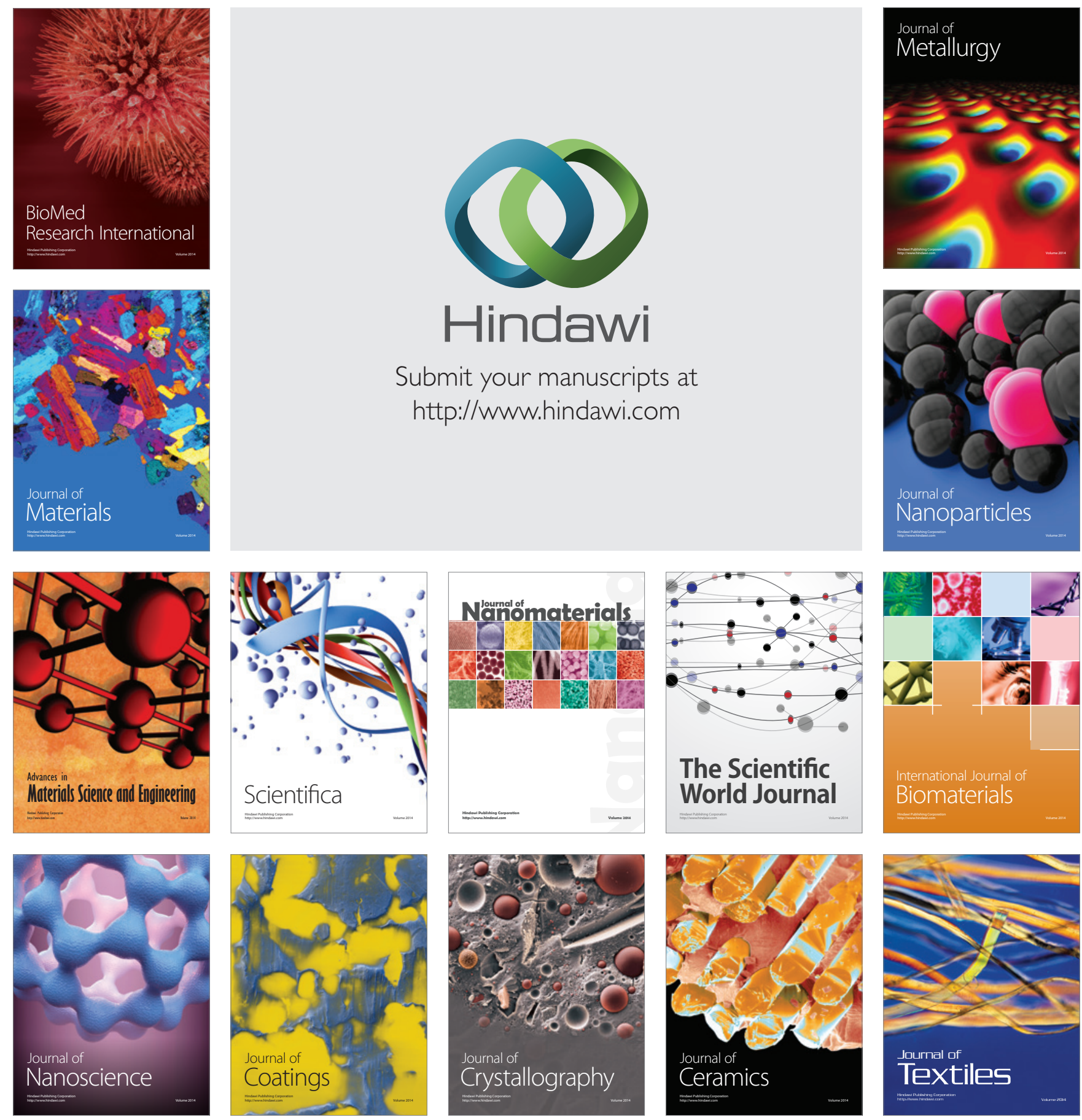